\title{
Study on Thermodynamics and Kinetics for the Reaction of Magnesium Diboride and Water by Microcalorimetry
}

\author{
Fengqi Zhao, Xiaoling Xing, Chuan Xiao, Rongzu Hu, Liang Xue, Hongxu Gao, Libai Xiao, Ting An \\ National Key Lab of Science and Technology on Combustion and Explosion, Xi' an Modern Chemistry \\ Research Institute, Xi'an, China \\ E-mail:npecc@163.com
}

Received October 3, 2010; revised December 15, 2010; accepted December 29, 2010

\begin{abstract}
An exothermic reaction between $\mathrm{MgB}_{2}$ and water was observed in our laboratory at high temperature, although no obvious reaction occurred at room temperature. The reaction process of $\mathrm{MgB}_{2}$ and water was therefore studied by using microcalorimetry. The results showed that the reaction enthalpies of $\mathrm{MgB}_{2}$ with water and the formation enthalpies of $\mathrm{MgB}_{2}$ at $T=(323.15,328.15,333.15$ and 338.15) $\mathrm{K}$ are $(-313.15$, $-317.85,-322.09,-329.27) \mathrm{kJ} \cdot \mathrm{mol}^{-1}$, and $(-238.96,-237.73,-236.50,-234.30) \mathrm{kJ} \cdot \mathrm{mol}^{-1}$, respectively. The standard enthalpy of formation and standard molar heat capacity of $\mathrm{MgB}_{2}$ obtained by extrapolation method are $-245.11 \mathrm{~kJ} \cdot \mathrm{mol}^{-1}$ and $246 \mathrm{~J} \mathrm{~mol}^{-1} \cdot \mathrm{K}^{-1}$, respectively. The values of activation energy $E$, pre-exponential factor $A$ and the reaction order for the reaction of $\mathrm{MgB}_{2}$ and water over the temperature range from $323.15 \mathrm{~K}$ to $338.15 \mathrm{~K}$ are $50.80 \mathrm{~kJ} \cdot \mathrm{mol}^{-1}, 10^{4.78} \mathrm{~s}^{-1}$ and about 1.346 , respectively. The positive values of $\Delta G^{\neq}$and $\Delta H^{\ddagger}$ and negative value of $\Delta S^{\ddagger}$ indicate that the reaction can take place easily above $314.45 \mathrm{~K}$.
\end{abstract}

Keywords: Magnesium Diboride, Water, Microcalorimetry, Thermodynamics, Kinetics

\section{Introduction}

Since the discovery of the superconductive property of magnesium diboride $\left(\mathrm{MgB}_{2}\right)$ in 2001, its synthetic methods [1-4], single crystals growth [5], spectral properties [6], superconductive characteristics [7], applications [8] and synthesis reaction mechanism under vacuum [9] are widely researched lately. Up to now, the interactional properties between $\mathrm{MgB}_{2}$ and solvents have never been investigated, however.

Boride is an important component of fuel-rich propellant, but it has difficulties in the ignition and combustion. One of the most effective methods to improve the performance of boron is to add combustible metals by chemical combination. In solid fuel ramjet's development, the propulsion application obtained by the reaction of $\mathrm{Mg}$ and water is the most popular topic of the water ramjet. For a deeper investigation of the potential applications of $\mathrm{MgB}_{2}$ in special solid propellants, the reaction of $\mathrm{MgB}_{2}$ and water was carried out by our laboratory to understand the physiochemical properties of $\mathrm{MgB}_{2}$ in solid propellants. We found for the first time that the $\mathrm{MgB}_{2}$ and water do not react visibly under room temperature, but when the temperature rises, an exothermic reaction happens obviously. The aim of this work is to describe the thermodynamic and kinetic properties of the reaction, and the investigation will offer valuable suggestions for the application of $\mathrm{MgB}_{2}$ on chemical propulsion aspect.

\section{Experimental}

\subsection{Sample and Equipment}

The sample $\left(\mathrm{MgB}_{2}\right)$ used in the experiment was prepared by Northwest Institute for Non-ferrous Metal Research. Its purity was improved from $95 \%$ up to $99.4 \%$ after recrystallized by our laboratory. The water was twice-distillated before use with its electrical conductivity being $(0.8-1.2) \times 10^{4} \mathrm{~S} \cdot \mathrm{m}^{-1}$.

All measurements were made using a RD496-2000 Calvet microcalorimeter. Two replicates of each sample were tested. The enthalpy of dissolution of $\mathrm{KCl}$ (spectrum purity) in distilled water measured at $298.15 \mathrm{~K}$ was 17.234 $\mathrm{kJ} \cdot \mathrm{mol}^{-1}$, which was an excellent accord with the literature value $17.241 \mathrm{~kJ} \cdot \mathrm{mol}^{-1}[10]$, showing that the device for measuring enthalpy used in this work was reliable. 


\subsection{Experiments}

\subsubsection{The Reaction of $\mathrm{MgB}_{2}$ and Distilled Water at a Heating Rate of $0.2 \mathrm{~K} \cdot \mathrm{min}^{-1}$}

Certain amount of $\mathrm{MgB}_{2}$ and distilled water were mixed in standard vessel at $298.15 \mathrm{~K}$. The whole device was put into the furnace. A heating rate of $0.2 \mathrm{~K} \cdot \mathrm{min}^{-1}$ was employed from $298.15 \mathrm{~K}$ to $348.15 \mathrm{~K}$. The product was dried under $313.15 \mathrm{~K}$ and the element analysis was then carried out.

\subsubsection{Element Analysis}

VarioE III element analysis equipment from German was employed to detect the content of $\mathrm{H}$ after the reaction. S4 Pioneer X-ray fluorescence spectrometer was used to determine the contents of both $\mathrm{Mg}$ and $\mathrm{B}$, and the field emission scanning electron microscopy from FEI Company in Holand was also used to determine the contents of $\mathrm{Mg}, \mathrm{B}$ and $\mathrm{O}$.

\subsubsection{The Reaction of $\mathrm{MgB}_{2}$ and Distilled Water at Different Temperatures}

The reaction of $\mathrm{MgB}_{2}$ and distilled water was carried out at $323.15,328.15,333.15$ and $338.15 \mathrm{~K}$, respectively.

\section{Results and Discussion}

\subsection{The Result of the Reaction of $\mathrm{MgB}_{2}$ and Distilled Water at a Heating Rate of 0.2 $\mathrm{K} \cdot \mathbf{m i n}^{-1}$}

The dependence of the heat flow of the reaction on reaction temperature (reaction time) was shown in Figure 1. From Figure 1, one can see that the reaction do not proceed at $298.15 \mathrm{~K}$. When the temperature rises up to $312.15 \mathrm{~K}$, the reaction of $\mathrm{MgB}_{2}$ and water begins and the reaction rate reaches a maximal point when the temperature rises to $314.45 \mathrm{~K}$.

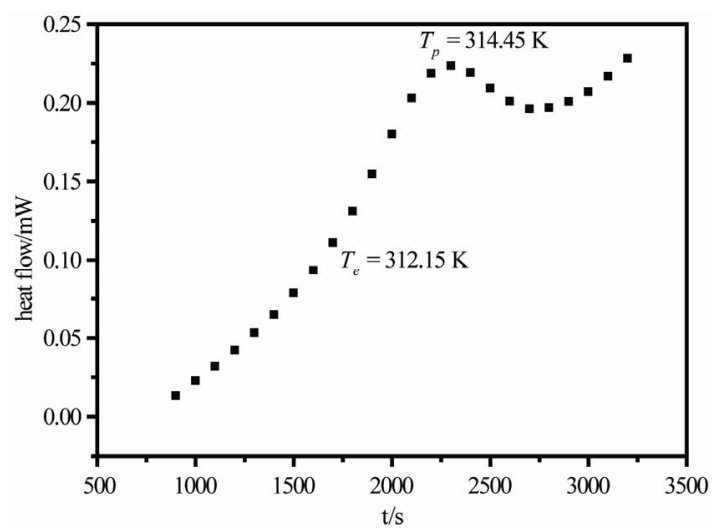

Figure 1. The heat flow curve of the reaction of $\mathrm{MgB}_{2}$ and water at a heating rate of $0.2 \mathrm{~K} \cdot \mathrm{min}^{-1}$.

\subsection{Element Analysis}

The element $\mathrm{H}$ was determined by VarioELIII element analysis equipment for three times, and the results were $3.00 \%, 3.02 \%$ and $3.00 \%$, respectively. The content of $\mathrm{Mg}$ was $36.63 \%$ by using the X-ray fluorescence spectrometer. The element analysis results obtained by the field emission scanning electron microscopy were shown in both Figure 2 and Table 1.

From the results of the element analyses, the reaction can be deduced as

$$
3 \mathrm{MgB}_{2}+6 \mathrm{H}_{2} \mathrm{O} \triangleq 4 \mathrm{~B}+3 \mathrm{Mg}(\mathrm{OH})_{2}+\mathrm{B}_{2} \mathrm{H}_{6} \uparrow
$$

The results of the element analyses are close to the theoretical calculation: B 19.81\%, Mg 33.43\%, O 44.01\%, $\mathrm{H} 2.75 \%$.

\subsection{The Standard Enthalpy of Formation of $\mathrm{MgB}_{2}$}

According to the Equation (2), we get the enthalpy of formation of $\mathrm{MgB}_{2}$ as in Equation (3).

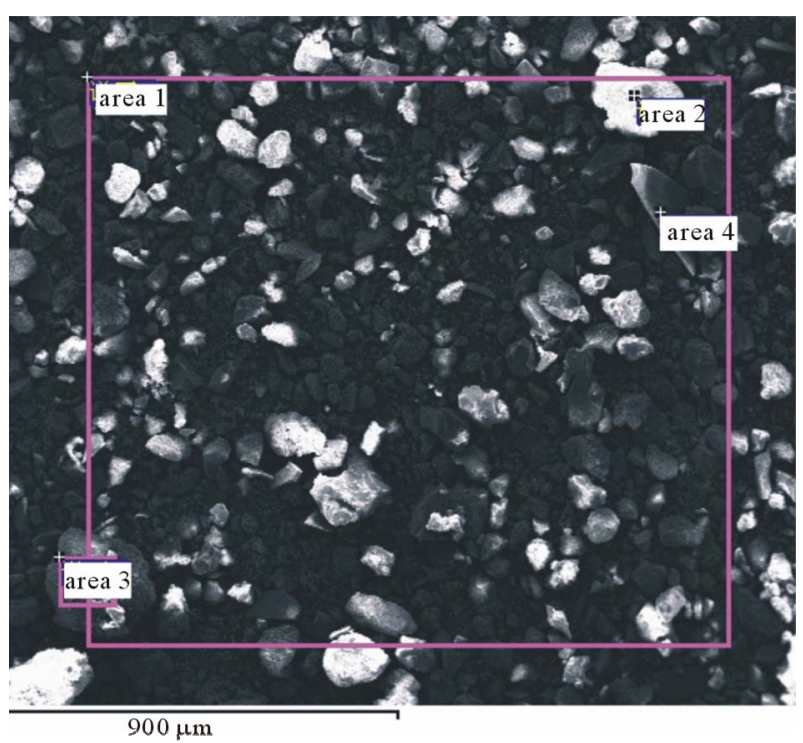

Figure 2. The electronic picture of the sample after the reaction.

Table 1. The content of each element.

\begin{tabular}{ccccc}
\hline No. & B & $\mathrm{O}$ & $\mathrm{Mg}$ & total \\
\hline & & & & \\
1 & 20.03 & 45.95 & 34.02 & 100.00 \\
2 & 19.96 & 46.18 & 33.86 & 100.00 \\
3 & 19.89 & 46.49 & 33.62 & 100.00 \\
4 & 20.06 & 46.41 & 33.53 & 100.00 \\
\hline
\end{tabular}




$$
\begin{gathered}
\Delta_{\mathrm{r}} H_{\mathrm{m}}=\Sigma \Delta_{\mathrm{f}} H_{\mathrm{p}}-\Sigma \Delta_{\mathrm{f}} H_{\mathrm{r}} \\
3 \Delta_{f} H_{\mathrm{m}}\left(\mathrm{MgB}_{2}\right)=4 \Delta_{f} H_{\mathrm{m}}(\mathrm{B})+3 \Delta_{f} H_{\mathrm{m}}\left(\mathrm{Mg}(\mathrm{OH})_{2}\right) \\
+\Delta_{f} H_{\mathrm{m}}\left(\mathrm{B}_{2} \mathrm{H}_{6}\right)-\Delta_{\mathrm{r}} H_{\mathrm{m}}-6 \Delta_{f} H_{\mathrm{m}}\left(\mathrm{H}_{2} \mathrm{O}\right)
\end{gathered}
$$

where $\Delta_{f} H_{\mathrm{m}}$ is the enthalpy of formation of each compound; $\Delta_{\mathrm{r}} H_{\mathrm{m}}$ is the enthalpy of reaction.

The enthalpy of formation of $\mathrm{MgB}_{2}$ could be obtained by Equation(4) [11].

$$
\begin{aligned}
& 3 \Delta_{f} H_{\mathrm{m}}\left(\mathrm{MgB}_{2}\right)=4\left[\Delta_{f} H_{\mathrm{m}}^{\theta}(\mathrm{B})+\int_{298.15}^{T} c_{\mathrm{B}} \mathrm{d} T\right] \\
& +3\left[\Delta_{f} H_{\mathrm{m}}^{\theta}\left(\mathrm{Mg}(\mathrm{OH})_{2}\right)+\int_{298.15}^{T} c_{\mathrm{Mg}(\mathrm{OH})_{2}} \mathrm{~d} T\right] \\
& +\left[\Delta_{f} H_{\mathrm{m}}^{\theta}\left(\mathrm{B}_{2} \mathrm{H}_{6}\right)+\int_{298.15}^{T} c_{\mathrm{B}_{2} \mathrm{H}_{6}} \mathrm{~d} T\right]-\Delta_{\mathrm{r}} H_{\mathrm{m}} \\
& -6\left[\Delta_{f} H_{\mathrm{m}}^{\theta}\left(\mathrm{H}_{2} \mathrm{O}\right)+\int_{298.15}^{T} c_{\mathrm{H}_{2} \mathrm{O}} \mathrm{d} T\right]
\end{aligned}
$$

Where $c$ is the molar heat capacity and $\Delta_{f} H_{\mathrm{m}}^{\theta}$ is the standard enthalpy of formation of each compound.

The determined reaction enthalpy of $\mathrm{MgB}_{2}$ and water at different temperatures were listed in Table 2. Other necessary data for calculation were listed in Table 3 .

By substituting the data taken from Tables $\mathbf{2}$ and $\mathbf{3}$ to Equation (4), the formation enthalpies of $\mathrm{MgB}_{2}$ at 323.15, $328.15,333.15$ and $338.15 \mathrm{~K}$ are $-238.96,-237.73$, -236.50 and $-234.30 \mathrm{~kJ} \cdot \mathrm{mol}^{-1}$, respectively.

Additionally, the standard enthalpy of formation, molar heat capacity and specific heat capacity of $\mathrm{MgB}_{2}$ is $-245.11 \mathrm{~kJ} \cdot \mathrm{mol}^{-1}, 246 \mathrm{~J} \cdot \mathrm{mol}^{-1} \cdot \mathrm{K}^{-1}$ and $5.36 \mathrm{~J} \cdot \mathrm{g}^{-1} \cdot \mathrm{K}^{-1}$, respectively, which indicates that $\mathrm{MgB}_{2}$ has high thermal capacity compared to other compounds.

Table 2. The enthalpies of reaction of $\mathrm{MgB}_{2}$ and water at different temperatures.

\begin{tabular}{cc}
\hline$T(\mathrm{~K})$ & $-\Delta_{\mathrm{r}} H_{\mathrm{m}}\left(\mathrm{kJ} \cdot \mathrm{mol}^{-1}\right)$ \\
\hline 323.15 & 313.55 \\
328.15 & 317.85 \\
333.15 & 322.09 \\
338.15 & 329.27 \\
\hline
\end{tabular}

Table 3. The parameters for calculation of the formation enthalpy of $\mathrm{MgB}_{2}$.

\begin{tabular}{lcc}
\hline & $c_{\mathrm{p}}\left(\mathrm{J} \cdot \mathrm{mol}^{-1} \cdot \mathrm{K}^{-1}\right)$ & $\Delta_{f} H^{\ominus}\left(\mathrm{kJ} \cdot \mathrm{mol}^{-1}\right)$ \\
\hline $\mathrm{H}_{2} \mathrm{O}(l)$ & 75.30 & -285.84 \\
$\mathrm{~B}(s)$ & 11.97 & 0 \\
$\mathrm{~B}_{2} \mathrm{H}_{6}(g)$ & 56.4 & 31.4 \\
$\mathrm{Mg}(\mathrm{OH})_{2}(s)$ & 77.03 & -924.66 \\
\hline
\end{tabular}

\subsection{The Kinetic Parameters of the Reaction of $\mathrm{MgB}_{2}$ and Water}

By putting the original data in Table 4, $-(\mathrm{d} H / \mathrm{d} t)_{i},\left(H / H_{\infty}\right)_{i}$, $H_{\infty}, i=1,2, \cdots, L$, into the kinetic equation (5) [12], the values of $n$ and $\ln k$ listed in Table 5 are obtained, where $n$ is the reaction order and $k$ the reaction rate constant.

$\ln \left[\frac{1}{H_{0}}\left(\frac{\mathrm{d} H}{\mathrm{~d} t}\right)_{i}\right]=\ln k+n \ln \left[1-\left(\frac{H}{H_{0}}\right)_{i}\right] i=1,2, \cdots, L$

From Table 5, one can see that the values of $n$ are close at different temperatures, and $\ln k$ increase slightly with temperature rising.

The Equation (6) was applied to calculate the values of activation energy $E$ and pre-exponential factor $A$ by the slope and the intercept of the linear.

$$
\ln k=\ln A-\frac{E}{R T}
$$

The value of $E$ is $50.80 \mathrm{~kJ} \cdot \mathrm{mol}^{-1}$ and $A$ is $10^{4.78} \mathrm{~s}^{-1}$.

With the data of $E$ and $A$, the entropy of activation $\left(\Delta S^{\neq}\right)$, enthalpy of activation $\left(\Delta H^{\neq}\right)$, and Gibbs free energy of activation $\left(\Delta G^{\neq}\right)$of the reaction processes of $\mathrm{MgB}_{2}$ and water under different temperatures were obtained by Equations (7) and (8) and shown in Table 6.

$$
\begin{gathered}
\Delta G^{\neq}=R T \ln \frac{R T}{N h k} \\
\ln \frac{k}{T}=\frac{-\Delta H^{\neq}}{R T}+\frac{\Delta S^{\neq}}{R}+\ln \frac{k_{B}}{h}
\end{gathered}
$$

where $k_{\mathrm{B}}$ is the Boltzmann constant $\left(1.3807 \times 10^{-23}\right.$ $\left.\mathrm{J} \cdot \mathrm{K}^{-1}\right)$, and $h$ is the Plank constant $\left(6.626 \times 10^{-34} \mathrm{~J} \cdot \mathrm{s}^{-1}\right)$.

Table 6 The values of $\Delta G^{\neq}, \Delta S^{\neq}$and $\Delta H^{\neq}$of the reaction process

The positive values of $\Delta G^{\neq}$and $\Delta H^{\neq}$, and the negative value of $\Delta S^{\neq}$show that the reaction can easily take place when the temperature is high enough.

\section{Conclusions}

1) The reaction of $\mathrm{MgB}_{2}$ and water will not happen until the environment temperature reaches $312.15 \mathrm{~K}$.

2) The enthalpies of formation of $\mathrm{MgB}_{2}$ at the temperatures of $(323.15,328.15,333.15$ and 338.15$) \mathrm{K}$ are $(-238.96,-237.73,-236.50$ and -234.30$) \mathrm{kJ} \cdot \mathrm{mol}^{-1}$, respectively. The standard enthalpy of formation of $\mathrm{MgB}_{2}$ obtained is $-245.11 \mathrm{~kJ} \cdot \mathrm{mol}^{-1}$.

3) The activation energy $E$ and pre-exponential factor $A$ of the reaction were obtained as $50.80 \mathrm{~kJ} \cdot \mathrm{mol}^{-1}$ and $10^{4.78} \mathrm{~s}^{-1}$ respectively. The values of $n$ are close under different temperatures, and $\ln k$ increases slightly with temperature rising. The entropy of activation $\left(\Delta S^{\neq}\right)$, enthalpy of activation $\left(\Delta H^{\neq}\right)$, and Gibbs free energy of 
Table 4. The original data of the reaction process of $\mathrm{MgB}_{2}$ and water at different temperatures.

\begin{tabular}{|c|c|c|c|c|c|c|}
\hline$T(\mathrm{~K})$ & $M(\mathrm{~g})$ & $m_{\text {water }}(\mathrm{g})$ & $t(\mathrm{~s})$ & $-(\mathrm{d} H / \mathrm{d} t)_{I}\left(\mathrm{~mJ} \cdot \mathrm{s}^{-1}\right)$ & $\left(H / H_{0}\right)_{i}$ & $\Delta H_{r}\left(\mathrm{~kJ} \cdot \mathrm{mol}^{-1}\right)$ \\
\hline \multirow[t]{16}{*}{323.15} & 0.0237 & 2.0010 & 300 & 2.5979 & 0.0349 & -313.5 \\
\hline & & & 600 & 2.6089 & 0.1117 & \\
\hline & & & 900 & 2.5500 & 0.1837 & \\
\hline & & & 1200 & 2.8444 & 0.261 & \\
\hline & & & 1500 & 2.8764 & 0.3428 & \\
\hline & & & 1800 & 2.6442 & 0.4219 & \\
\hline & & & 2100 & 2.2974 & 0.4921 & \\
\hline & & & 2400 & 1.9486 & 0.5524 & \\
\hline & & & 2700 & 1.6397 & 0.6035 & \\
\hline & & & 3000 & 1.3934 & 0.6465 & \\
\hline & & & 3300 & 1.1892 & 0.6833 & \\
\hline & & & 3600 & 1.0295 & 0.7148 & \\
\hline & & & 3900 & 0.8948 & 0.7421 & \\
\hline & & & 4200 & 0.7824 & 0.7659 & \\
\hline & & & 4500 & 0.6912 & 0.7868 & \\
\hline & & & 4800 & 0.6111 & 0.8054 & \\
\hline \multirow[t]{16}{*}{328.15} & 0.0248 & 2.0008 & 300 & 1.3733 & 0.7485 & -317.8 \\
\hline & & & 600 & 1.1056 & 0.7834 & \\
\hline & & & 900 & 0.9304 & 0.8121 & \\
\hline & & & 1200 & 0.7702 & 0.8360 & \\
\hline & & & 1500 & 0.6424 & 0.8559 & \\
\hline & & & 1800 & 0.5498 & 0.8727 & \\
\hline & & & 2100 & 0.472 & 0.8872 & \\
\hline & & & 2400 & 0.4106 & 0.8996 & \\
\hline & & & 2700 & 0.3597 & 0.910 & \\
\hline & & & 3000 & 0.3181 & 0.9201 & \\
\hline & & & 3300 & 0.2815 & 0.9285 & \\
\hline & & & 3600 & 0.2528 & 0.9360 & \\
\hline & & & 3900 & 0.2275 & 0.942 & \\
\hline & & & 4200 & 0.2050 & 0.9489 & \\
\hline & & & 4500 & 0.1869 & 0.9544 & \\
\hline & & & 4800 & 0.1716 & 0.9595 & \\
\hline \multirow[t]{7}{*}{333.15} & 0.0348 & 2.0011 & 300 & 5.8786 & 0.0333 & -322.1 \\
\hline & & & 600 & 8.2060 & 0.1682 & \\
\hline & & & 900 & 9.0554 & 0.3347 & \\
\hline & & & 1200 & 7.3002 & 0.4903 & \\
\hline & & & 1500 & 5.2226 & 0.6072 & \\
\hline & & & 1800 & 3.6957 & 0.6901 & \\
\hline & & & 2100 & 2.6709 & 0.7492 & \\
\hline
\end{tabular}




\begin{tabular}{|c|c|c|c|c|c|c|}
\hline & & & 2400 & 1.9952 & 0.7925 & \\
\hline & & & 2700 & 1.5389 & 0.8253 & \\
\hline & & & 3000 & 1.2169 & 0.8510 & \\
\hline & & & 3300 & 0.9788 & 0.8715 & \\
\hline & & & 3600 & 0.8043 & 0.8881 & \\
\hline & & & 3900 & 0.6734 & 0.9019 & \\
\hline & & & 4200 & 0.5703 & 0.9136 & \\
\hline & & & 4500 & 0.4889 & 0.9235 & \\
\hline & & & 4800 & 0.4260 & 0.9320 & \\
\hline \multirow[t]{7}{*}{338.15} & 0.0219 & 2.0006 & 300 & 9.0078 & 0.3364 & -329.27 \\
\hline & & & 600 & 6.7631 & 0.5705 & \\
\hline & & & 900 & 4.2677 & 0.7286 & \\
\hline & & & 1200 & 2.6545 & 0.8267 & \\
\hline & & & 1500 & 1.7327 & 0.8893 & \\
\hline & & & 1800 & 1.1941 & 0.9312 & \\
\hline & & & 2100 & 0.8504 & 0.9604 & \\
\hline
\end{tabular}

Table 5. The values of $n$, Ink and the correlation coefficient $r$ for the reaction of $\mathrm{MgB}_{2}$ and $\mathrm{H}_{2} \mathrm{O}$.

\begin{tabular}{cccc}
\hline$T / \mathrm{K}$ & $n$ & $\ln k$ & $r$ \\
\hline 323.15 & 1.390 & -10.212 & 0.9999 \\
328.15 & 1.317 & -9.892 & 0.9988 \\
333.15 & 1.389 & -9.556 & 0.9987 \\
338.15 & 1.289 & -9.394 & 0.9891 \\
mean & 1.346 & & \\
\hline
\end{tabular}

Table 6. The values of $\Delta G^{\neq}, \Delta S^{\neq}$and $\Delta H^{\neq}$of the reaction process.

\begin{tabular}{cccc}
\hline$T(\mathrm{~K})$ & $\Delta \boldsymbol{G}^{\neq}\left(\mathrm{kJ} \mathrm{mol}^{-1}\right)$ & $\Delta H^{\mp}\left(\mathrm{kJ} \mathrm{mol}^{-1}\right)$ & $\Delta \boldsymbol{S}^{\neq}\left(\mathrm{J} \mathrm{mol}^{-1} \mathrm{~K}^{-1}\right)$ \\
\hline 323.15 & 391.37 & 142.29 & -770.79 \\
328.15 & 396.59 & 144.50 & -768.23 \\
333.15 & 401.74 & 146.69 & -765.56 \\
338.15 & 407.36 & 148.88 & -764.38 \\
\hline
\end{tabular}

activation $\left(\Delta G^{\ddagger}\right)$ of the reaction processes of $\mathrm{MgB}_{2}$ and water under different temperatures show that the reaction can easily take place when the temperature is high enough.

\section{Acknowledgements}

Financial assistance from the Science and Technology Foundation of the National Key Lab of Science and Technology on Combustion and Explosive in China (Grant No. 9140C3501020901) is gratefully acknowledged.

\section{References}

[1] J. Schmidt, W. Schnelle, Y. Grin and R. Kniep, "Pulse Plasma Synthesis and Chemical Bonding in Magnesium Diboride," Solid State Sciences, Vol. 5, No. 4, 2003, pp. 535-539. doi:10.1016/S1293-2558(03)00026-8

[2] A. O'Brien, B. Villegas and J. Gu, "Sputtered Magnesium Diboride Thin Films: Growth Conditions and Surface Morphology," Physica C, Vol. 496, 2009, pp. 39-43.

[3] G. Amico, A. Trolio, A. Morone, S. Orlando and A. Santagata, "Optical Characterization of Magnesium Diboride 
plasma Plume Induced by Pulsed Laser Ablation," Applied Surface Science, Vol. 208-209, 2003, pp. 96-100. doi:10.1016/S0169-4332(02)01342-9

[4] T. Prikhna, W. Gawalek, Y. Savchuk, N. Sergienko and V. Moshchil, "High-Pressure-High-Temperature Synthesis of Magnesium Diboride with Different Additions," Physica C, Vol. 460-462, 2007, pp. 595-597. doi:10.1016/j.physc.2007.04.110

[5] C. Dancer, P. Mikheenko, A. Bevan, J. Abell, J. Todd and C. Grovenor, "A Study of the Sintering Behaviour of Magnesium Diboride," Journal of the European Ceramic Society, Vol. 29, No. 9, 2009, pp. 1817-1824. doi:10.1016/j.jeurceramsoc.2008.09.025

[6] Z. Cheng, X. Wang, A. Pan, H. Liu and S. Dou, "Characterization and Growth of Magnesium Diboride Single Crystals," Journal of Crystal Growth, Vol. 263, 2004, pp. 218-222.

[7] R. Ribeiro, S. Budko, C. Petrovic and P. Canfield, "Carbon Doping of Superconducting Magnesium Diboride," Physica C, Vol. 384, No. 3, 2003, pp. 227-236. doi:10.1016/S0921-4534(02)02331-6

[8] R. King, "Chemical Bonding Topology of Superconduc- tors 5. The similarities between Magnesium Diboride and Cuprate Superconductors and the Role of Subvalent Magnesium," Polyhedron, Vol. 21, No. 23, 2002, pp. 2347- 2350. doi:10.1016/S0277-5387(02)01183-X

[9] S. Bruttia, G. Balduccia, G. Gigli, A. Ciccioli, P. Manfrinetti and A. Palenzon, "Thermodynamic and Kinetic Aspects of Decomposition of $\mathrm{MgB}_{2}$ in Vacuum: Implications for Optimization of Synthesis Conditions," Journal of Crystal Growth, Vol. 289, 2006, pp. 578-586.

[10] V. Marthada, "The Enthalpy of Solution of SRM 1655 $(\mathrm{KCl})$ in $\mathrm{H}_{2} \mathrm{O}$," Journal of Research of the National Bureau of Standards, Vol. 85, No. 6, 1980, pp. 467-481.

[11] S. Gao, S. Chen, B. Jiao, Y. Ren, R. Hu, F. Zhao and Q. Shi, "Thermochemistry on Coordination Behavior of Lanthanum Chloride Hydrate with Diethylovm Diethyldithiocarbamate," Acta Chim Sin (in Chinese), Vol. 61, 2003, pp. 2020-2024.

[12] R. Z. Hu and Q. Z. Shi, "Thermal Analysis Kinetics (in Chinese)," Science Press, Beijing, 2001. 